\title{
Boosting $21^{\text {st }}$ Century Skills through Moroccan ELT Textbooks
}

\author{
Hassan Ait Bouzid \\ Doctoral Studies Center on Language, Culture and Society, Faculty of Letters and \\ Human Sciences, Chouaib Doukkali University, El Jadida, Morocco \\ hassan.aitbouzid@gmail.com
}

\begin{abstract}
Research shows that the changing realities of the $21^{\text {st }}$ century necessitate a fundamental shift in language education towards promoting $21^{\text {st }}$ Century Skills. This paper investigates the extent to which three Moroccan ELT textbooks currently used in teaching second year Baccalaureate students in public high school provide activities that help learners build skills that match the needs of the $21^{\text {st }}$ century. It also explores the types of activities that are used to promote these skills and eventually suggests some ways in which these skills could be promoted effectively in future textbooks. It draws the attention of teachers, educational policy makers, school inspectors and textbook designers to the importance of incorporating activities that facilitate the acquisition of a set of skills that meet the demands of the $21^{\text {st }}$ century. The study adopts a concurrent triangulation design and used content analysis as a mixed method that combines quantitative and qualitative techniques. Quantitative findings show that textbooks tend to provide very little activities that enable learners to develop their ICT skills. Also, they do not encourage learners to think creatively and develop career and life-skills. Qualitative findings indicate that textbooks tend to present these skills in a traditional way that does not cater for the $21^{\text {st }}$ century context. This paper concludes with suggesting activities that will help future textbooks present $21^{\text {st }}$ Century Skills in ways that will facilitate the transfer of these skills to Moroccan English language learners.
\end{abstract}

Keywords: $21^{\text {st }}$ Century Skills, textbook evaluation 


\section{INTRODUCTION}

In an ever-growing, continuously changing world, traditional teaching and learning is facing numerous multidimensional challenges that defy its ability to responds to the versatile needs and interests of students, teachers and job markets of the $21^{\text {st }}$ century. As information communication technology advances and spreads its influence on almost every aspect of human life, it becomes apparent that educational systems must consider a new set of skills that befit the technological dependence emblematic to the twenty first century. Therefore, radical but smooth changes need to be incorporated within every country's educational policy making, the plethora of the teaching learning approaches, methods and techniques they are adapting as well the tools and materials they are using for the purpose of matching the ultimate teaching learning outcomes with the socio-economic and political demands for global citizens. Nurhayati (2008a) stated that the world of education needs improvement of universities, colleges, senior high schools, junior high schools as well preschools. Most of them should be provided with suitable approaches or a course design which is carried out in their process of teaching language to the students.

More particularly, teachers are responsible for preparing learners that are compatible with the $21^{\text {st }}$ century. However, they are the weakest link in a longer chain that comprises educational policy makers, teacher trainers, school inspectors, school administrators, researchers and textbook designers who should join efforts to provide teachers with best practices, materials and guidance on how to effectively teach skills that are compatible with the new realities of the $21^{\text {st }}$ century. Within the classroom context, teachers resort to the teaching materials to help them fulfill this task. In most cases, teachers rely on textbooks to provide insights and guidance on what to teach and how to teach it despite the fact that textbooks themselves are not perfect. Textbooks remain at the heart of every teaching learning context. Richards (2001) reckons that textbooks will undoubtedly remain central to every language teaching context despite the technological advances not only because they provide resources for both learners and teachers, but also because they serve to mold the official guidelines into concrete texts, exercises, illustrations and practice activities. However, many researchers (Cunningsworth, 1995; Litz, 2005; Hutchinson \& Torres, 1994; Jibreel 2015; McDonough \& Shaw, 2003) maintain that textbooks are to a great extent susceptible of containing problems related to social, cultural and linguistic issues as well as to pedagogical issues concerning the provision of activities that enable students to appropriately function within their immediate sociocultural, political and economic contexts. These researchers point out that these weaknesses, though not inherent in textbooks, can affect learners' attitudes towards their immediate environments and their attitudes towards the teaching learning process as well. Therefore, the content of textbooks must be continuously assessed in order to examine the extent to which this content agrees with learners' needs and interests on the one hand, and with the objectives of the curriculum and the demands of the job market on the other.

This study is built on the assumption that the practice of textbook evaluation is of crucial importance as an integral part of the practices of educational 
practitioners because of the central role coursebooks occupy in the teaching-learning process. Numerous have been those researchers who actually attribute the value of textbook evaluation to the indispensability of coursebooks as core elements in the educational act. For instance, Sheldon (1988) points out that the textbook remains an essential element in every classroom activity since it represents the visible heart of any ELT program while Garinger (2002) contends that a textbook is at the heart of every classroom because it can serve different purposes: it can be used as a core resource, as a source of supplemental material, as an inspiration for classroom activities and even as the curriculum itself.

Nevertheless, Sheldon (1988) and Garinger (2002) consider that textbooks oftentimes constitute a problem that may become an educational failure in some extreme situations which insistently necessitates the definition and application of systematic criteria for assessing textbooks. In other words, they argue for a systematic textbook evaluation that bases itself on concrete predetermined criteria designed especially for the purpose of identifying and solving problems that textbooks may contain. In fact, much of the justification for the practice of textbook evaluation is associated with the importance textbooks have in the teaching-learning process. Yet, it is to maintain that textbooks gain more value through textbook evaluation as the usefulness, appropriateness and effectiveness of a textbook can only be accredited through the practice of a systematic textbook evaluation. It remains then that textbooks and textbook evaluation are intertwined into a reciprocal relationship of interdependence where the value of one is only determined by the value of the other. In short, for textbooks to achieve the desired learning outcomes effectively, their content, approach and methodology must be effectively evaluated.

The present paper responds to need of applying the practice of textbook evaluation to identify the role select Moroccan ELT textbooks play in endowing students with skills that suits the $21^{\text {st }}$ century. It also responds to an expectedly inevitable introduction of new English language teaching textbooks into Moroccan public high schools It draws the attention of teachers, school inspectors, educational policy makers and, most importantly, textbook designers to the vital role textbooks can play in helping students learn effective $21^{\text {st }}$ Century Skills that will enable them to function appropriately and effectively within a global community of English language speakers. In addition, it aims to investigate the extent to which three Moroccan ELT textbooks currently used in public high schools provide activities that help students develop a set of $21^{\text {st }}$ century skills indicated in the American Council on the Teaching of Foreign Languages [ACTFL] (2011). This paper also aims to suggest ways in which future Moroccan ELT textbooks could improve their content by including more activities targeting the teaching of 21 st century skills.

The study is positioned within the theoretical framework of the StandardsBased Approach which frames the teaching and learning of English as a foreign language in Moroccan public high schools (Ministry of National education, 2007). According to the ACTFL (2011), this approach present a fertile ground where to cultivate learners that are capable of communicating effectively with people from different cultures while insightfully comparing their local languages and cultures with other foreign languages and cultures. The Standards-Based Approach also 
allows foreign language learners to develop the ability to make inter-disciplinary connections than can only deepen the knowledge and skills they learn from English language and other subjects. More interestingly, the adopted approach caters for encouraging strategic learning that enables students to continue their own education as life-long learners long after their school career has finished (ACTFL, 1995). The three textbooks considered for investigation in this study supposedly adhere to the theoretical principles of this approach; therefore they should present activities that facilitate the teaching of 21 st century skills.

Three main questions drive the present study; they are:

1. To what extent do select Moroccan ELT textbooks promote $21^{\text {st }}$ century skills?

2. What kind of $21^{\text {st }}$ century skills are promoted by the select ELT textbooks under study?

3. What kind of activities can be used to enrich students' $21^{\text {st }}$ century skills through ELT textbooks?

\section{LITERATURE REVIEW}

Incorporating a set of skills that satisfy the needs of the $21^{\text {st }}$ century learners in the curricula used in teaching and learning of English as a foreign language has become a priority. Learners nowadays are no longer expected to base their success on their ability to perform manual work; rather, they are supposed to demonstrate an indispensable ability to search for, find, share and use information to solve various and complex problems. Students' success today is evaluated on their ability to adapt to new situations through showing how innovative and creative they are as well as exhibiting their mastery of various information communication technologies which have become unavoidable in the world of the $21^{\text {st }}$ century (National Education Association [NEA], 2012).

To perform this shift and overcome the new challenge of this era, a set of $21^{\text {st }}$ Century Skills must be introduced to and taught to students. In addition to fostering learners' communication skills, language classes should enable learners to develop skills that will enable them to identify and retrieve relevant and useful information, organize it and evaluate its accuracy, relevance, usefulness and efficiency. They are also required to teach skills that encourage learners to work collaboratively with others despite their socio-cultural differences, listening to their opinions and providing formative feedback that emanates from a constructive strategic critical thinking. Moreover, $21^{\text {st }}$ century students should be able to function cross-culturally and think creatively and innovatively not only because globalization has nearly eliminated borders and shortened distances among countries, but also because the job market is constantly changing and the life-span of jobs is becoming smaller. In this respect, today's learners need to be able to develop professional career and lifeskills such as productivity, accountability, leadership, responsibility and sociability (NEA, 2012; Pacific Policy Research Center [PPRC], 2010; Scott, 2015).

A number of strategies can be used to foster $21^{\text {st }}$ Century Skills. PPRC (2010) and Partnership for $21^{\text {st }}$ Century Skills [P21] (2011) suggest an action plan that revolves around six main elements. First, teaching these skills should be 
emphasized in core subjects including, though not limited to, civic literacy, global awareness, financial literacy, health literacy, environmental literacy, visual literacy, media literacy; information literacy and technology literacy. Second, the teaching and learning process should give prominence to the 'how' by focusing on strategic learning that aims to provide learners with effective learning strategies and skills rather that teaching content. The third element consists of using $21^{\text {st }}$ century tools in the process of teaching and learning through the use modern information communication technologies this process. The fourth element is that teachers should teach $21^{\text {st }}$ century content that reflects the immediate authentic reality of the students. The fifth element entices teachers to contextualize the teaching learning process within an authentic $21^{\text {st }}$ century context that is familiar to the students, while the sixth element highlights the importance of using $21^{\text {st }}$ century assessment techniques which measure $21^{\text {st }}$ Century Skills. Therefore, the successful teaching of $21^{\text {st }}$ Century Skills is highly dependent on the extent to which the content, methods, tools and classroom contexts are relevant to the $21^{\text {st }}$ century; any discordance is susceptible of flawing the intended outcomes.

A number of activities could be devised to effectively help young learners promote the required set of $21^{\text {st }}$ Century Skills. NEA (2012), P21 (2011), PPRC (2010) and Scott (2015) provide criteria for effective $21^{\text {st }}$ Century Skill activities. One major characteristic of these activities is that they should focus on real-world problems and processes. They should provide learners with authentic problematic situations which students may relate with the outside world. Real-life-like problems increase students' motivation and trigger their attention because they know that they may face such problems outside the classroom contexts. In addition, effective $21^{\text {st }}$ century skills activities should support inquiry-based learning experiences which involve students in the process of building and understanding concepts through asking questions, searching for answers, discussing them with colleagues and reflecting upon different possible answers. These activities should also provide opportunities for collaborative learning experiences where learners work together in groups or teams, share responsibilities and exchanges feedback and leadership. More importantly, activities designed to promote $21^{\text {st }}$ Century Skills should focus on teaching learning strategies and skills rather than learning and memorizing content. These activities should enable learners with the skills and strategies needed to communicate effectively, solve problems, think critically and creatively and work collaboratively; all of which skills are highly valued in $21^{\text {st }}$ century job market.

\section{RESEARCH METHOD}

The study adopted a concurrent triangulation design using content analysis as a mixed method that combines both quantitative and qualitative techniques (Krippendorff, 2013). The objective is to evaluate the content of three Moroccan ELT textbook currently used in teaching second year Baccalaureate students in public schools, namely Gateway to English 2 (Hassim, Blibil \& Rasmy, 2007), Insights into English 2 (Najbi \& El Haddad, 2007) and Ticket to English 2 (Hammani, Ahssen \& Tansaoui, 2007). These textbooks are locally designed and are used as national textbooks that are used interchangeably to teach the final level in 
Moroccan public high schools. Unfortunately, teachers do not have the right to choose which textbook to use as this is the task of the local authorities which distribute textbooks among schools equally and randomly.

The three textbooks were analyzed both quantitatively and qualitatively to examine the extent to which they presented activities that can develop learners' $21^{\text {st }}$ Century Skills. The purpose of the quantitative analysis is to identify whether the number of these activities is sufficient for promoting these skills and whether the number of activities is distributed equally among the different $21^{\text {st }}$ Century Skills so that no skill is undermined. The purpose of the qualitative analysis is to identify the kind of activities that are used in promoting the different skills and the quality of the presentation of the instructions.

The quantitative analysis consisted of making frequency counts of activities that provided texts, dialogues and exercises whose aim is to teach any of the $21^{\text {st }}$ Century Skills and illustrating them in tables. Each table was followed by a descriptive qualitative analysis which describes ways in which different activities used these texts, dialogues and exercises to promote the set of $21^{\text {st }}$ Century Skills identified in these three textbooks. The interpretation of both quantitative and qualitative data is fused with the qualitative description that follows each table since it is impossible to separate qualitative analysis from interpretation according to Cohen, Manion and Morrison, (2007).

\section{FINDINGS AND DISCUSSION}

This study analyzed three Moroccan second year Baccalaureate ELT textbooks to identify the extent to which these textbooks presented activities that promoted $21^{\text {st }}$ Century Skills among learners. The results shown in Table 1 demonstrate the number of such activities identified in these three textbooks:

Table 1: number of activities promoting $21^{\text {st }}$ Century Skills in textbooks

\begin{tabular}{|c|c|c|c|c|}
\hline & Gateway 2 & Insights 2 & Ticket 2 & Total \\
\hline $\begin{array}{l}\text { Activities promoting } 21^{\text {st }} \text { Century } \\
\text { Skills }\end{array}$ & 30 & 34 & 31 & 95 \\
\hline
\end{tabular}

The finding illustrated in Table 1 reveal that textbooks contained an important number of these activities and that there is no great discrepancy in terms of number of activities contained in each textbook. Gateway to English 2 presented the smallest number of activities (30), while Ticket to English 2 contained 31 and Insights into English 2 provided the highest number of activities with 34 activities.

Taking into consideration the fact that each textbook is divided into 10 units, it could be inferred that each unit had at least 3 activities aiming at teaching $21^{\text {st }}$ Century Skills. However, it is observed that these activities did not focus on one particular skill, but rather, each activity targeted multiple skills at a time. Table 2 illustrates this idea in more details:

Table 2: Frequency of $21^{\text {st }}$ Century Skills promoted in various activities $\begin{array}{lllll}21^{\text {st }} \text { Century Skills } & \text { Gateway } 2 & \text { Insights } 2 & \text { Ticket } 2 & \text { Total }\end{array}$ 


\begin{tabular}{lllll}
\hline Communicate clearly & 23 & 27 & 25 & 75 \\
Cross cultural understanding & 21 & 19 & 22 & 62 \\
Work collaboratively & 20 & 19 & 27 & 66 \\
Think critically & 24 & 23 & 16 & 63 \\
Think creatively & 6 & 5 & 7 & 18 \\
Use ICT effectively & 4 & 6 & 4 & 14 \\
Develop professionally and socially & 7 & 12 & 8 & 27 \\
TOTAL & 105 & 111 & 109 & 325 \\
\hline
\end{tabular}

Table 2 demonstrates that textbooks presented activities that promote various skills at a time. Gateway to English 2 tackled the 7 skills 105 times in 30 activities with an average of 3.5 skills per activity. Insights into English 2 presented the 7 skills 111 times in 34 activities, with an average of 3.2 skills per activity. Ticket to English 2 tackled the seven skills 109 times in 31 activities, with an average of 3.5 skills per activity. Table 2, therefore, shows that activities presented by Gateway to English 2 and Ticket to English 2 are actually richer in terms of the number of skills included in each activity.

Table 2 also reveals that some skills were more frequently presented than others. The three textbooks frequently stressed skills enticing students to communicate clearly (75 times), work collaboratively (66 times), think critically (63 times) and cross-cultural understanding (62 times). Gateway to English 2 frequently taught critical thinking skills which were tackled 24 times, communication skills which were mentioned 23 times and working collaboratively which were discussed 20 times alongside cross-cultural understanding skills which were visited 21 times, respectively. Insights into English 2 is similar to Gateway to English 2 except for the fact that the former gave prominence to effective communication skills which were included in 27 activities. Skills enticing student to work collaboratively were highlighted 27 times in Ticket to English 2 followed by skills of effective communicative and cross-cultural understanding with a frequency rate reaching 25 times and 22 times, respectively.

The three textbooks did not provide enough space for three $21^{\text {st }}$ Century Skills. Skills targeting students' ability to think creatively, use ICT effectively and develop professionally and socially were not as frequently targeted in activities as the previously mentioned skills. For instance, only six activities in Gateway to English 2 included creative thinking skills as compared to 5 in Insights into English and 7 in Ticket to English 2. In addition, only four activities in both Gateway to English 2 and Ticket to English 2 contained skills aiming at enabling students to use ICT effectively as compared to 6 of such activities identified in Insights into English 2. Moreover, the ability to develop professionally and socially was contained only in 7, 8 and 12 activities in Gateway to English 2, Ticket to English 2 and Insights into English 2, respectively.

The three textbooks relied on different kinds of activities to boost $21^{\text {st }}$ Century Skills. The dominance of skills promoting students ability to communicate clearly is to a great extent congruent with the nature of foreign language teaching textbooks whose aim is to improve students' ability to communicate effectively in a 
foreign language. To achieve this goal, textbooks rely heavily on activities fostering interpersonal, interpretive and presentational communication skills through a series of dialogues, conversations, readings texts, listening activities, writing assignments and functional practice activities. It is also observed that the ability to work collaboratively is fostered through a variety of activities such as grammar exercises, functional practices, writings, discussions and project works. These activities encourage students to work collaboratively in groups or in pairs to promote their ability to share and exchange responsibility, listen for and provide feedback and provide positive support for other group members.

Different types of activities were used to promote students' ability to think critically. In fact critical thinking skills were promoted mainly through post reading and post listening activities in which learners were asked to respond critically to the reading/listening texts. Critical thinking skills were also promoted through speaking activities asking students to evaluate opinions and thoughts of their classmates or through speaking activities enticing them to think reflectively about their own actions, thoughts and emotions. Research revealed that teacher modeling of reading practice brings the students about nurturing good reading habits in English (Iftanti, 2015). Critical thinking skills identified and promoted through activities in these textbooks comprised the ability to build arguments and provide concrete evidence, the ability to think systematically as well as the ability to tolerate cultural differences.

Cross cultural understanding skills were developed through reading activities, listening activities, writing activities, dialogues and discussions. Students were occasionally asked to compare and contrast aspect of both local and foreign cultures to identify similarities and differences among different cultures. These activities were also used to foster students' understanding of the relationship between cultural perspectives and cultural practices of both foreign and local cultures on the one hand, and between cultural perspectives and cultural products of both cultures on the other. The objective of these activities is to help students tolerate cultural differences and co-exist peacefully with other people despite their differences.

However, the scarcity of activities promoting creative thinking skills and ICT skills is apparent throughout the three textbooks. These textbooks presented a limited number of activities enhancing creative thinking skills because of the noticeable shortage regarding project works, games, creative writing and problem solving activities. Textbooks also presented a limited number of activities fostering students ICT skills because most activities encouraged students to use skills that they have already mastered. For example, some writing activities teach students the basics of e-mail writing while students actually know how to write an e-mail. Few project works encourage students to present their finding in PowerPoint presentation format, while fewer activities such as vocabulary and reading activities to search for information on the internet.

The three textbooks also presented an insufficient number of activities that foster learners' professional and social skills. The three textbooks provided activities which are more concerned with providing learners with skills which would help 
them in their schooling, but they did not include enough activities that aimed to prepare these learners for their professional and social life. This is due to the fact that the three textbooks provided little activities that are associated with authentic real-life professions from which students could learn about the skills which would help students set up a successful professional career in these professions. For instance, Insights into English 2 is concerned with preparing students for a professional career in journalism as it provided a number of activities that teach students skills related to interviewing, conducting surveys, conducting opinion polls and searching for information Ticket to English is concerned with fostering learners' study skills through a number of activities that aim to help learners develop their ability to manage their time, think critically, use SQ4R, keep record of their studies, take notes effectively and get prepared to succeed in exams and tests. Gateway to English 2 has to a great extent succeeded in providing a balanced mixture of activities that foster learners' social and professional skill despite their quantitative insufficiency. Along with providing the necessary set of study skills such as knowing about learning styles, effective note-taking, effective learning of vocabulary, effective ways of giving presentations and preparing one's self for the university, the latter textbook has provided activities that aimed to familiarize students with skills required for a professional career in both journalism, tourism and banking through providing activities that encouraged students to use interviewing skills, writing action plans of projects, making a brochure, transform information into diagrams, learning about the development of banks, brain storming and mindmapping.

The findings revealed a number of discrepancies between the ways in which the three textbooks dealt with $21^{\text {st }}$ Century Skills and the guidelines indicated by the literature. First, the number of activities that promoted these skills is not only insufficient but also imbalanced as some skills are more targeted than others. Second, these skills are presented in traditional contents that are incoherent with the core-subjects suggested by PPRC (2010) and P21 (2011). Third, these $21^{\text {st }}$ Century Skills are taught using traditional tools and materials that are incompatible with the nature of the $21^{\text {st }}$ Century because they rarely encourage students to use modern digital and ICT tools. Finally, the three textbooks did not provide assessment criteria that would enable learners and teachers to evaluate the extent to which a given skills was successfully or unsuccessfully learnt.

\section{CONCLUSION AND IMPLICATIONS}

The purpose of this study was to investigate the extent to which three Moroccan ELT textbooks currently used in teaching second year Baccalaureate level in public high schools empower students with skills that are compatible with the needs and requirements of the $21^{\text {st }}$ century. It draws the attention of teachers, educational policy makers, school inspectors and textbook designers to the necessity of including activities that have the potential of boosting learners' $21^{\text {st }}$ Century Skills. The review of the literature revealed the importance of enabling learners with seven main skills that are considered as main $21^{\text {st }}$ century skills. The first skill is the ability to communicate clearly and the second one is the ability of cross-cultural 
understanding. The third skill is the ability to think critically, while the fourth skill is the ability to think creatively. The fifth and the sixth skills are the ability to work collaboratively and the ability to use information communication technology effectively. The last skill is the ability to develop professionally and socially.

The research adopted a concurrent triangulation design relying on content analysis as a mixed method using both quantitative and qualitative data analysis techniques. The findings of the quantitative analysis revealed that the three textbooks did not provide a sufficient number of activities that would help foster the aforementioned skills among learners. They also demonstrated that the three textbooks did not treat these skills equally because the majority of activities were concerned with communication skills, cross-cultural understanding skills, collaborative working skills and critical thinking skills, respectively. Other skills related to creative thinking skills, ICT skills and professional development skills were given smaller attention within different activities. The qualitative analysis demonstrated that the nature of the activities which presented these skills were to a great extent incompatible with the nature of activities required for developing $21^{\text {st }}$ Century Skills. The three textbooks relied on traditional activities that were conventionally used in ELT textbooks to develop reading, writing, listening and speaking skills. To bridge this gap, the following suggestions are made:

- Textbooks should incorporate $21^{\text {st }}$ Century Skills in every activity so that learners will be exposed to these skills throughout the whole school year

- Textbooks should encourage learners to use ICT skills both inside and outside the classroom through encouraging mobile learning and using social networks as learning sources

- Textbooks should encourage learners to think creatively by enticing them to present their learning performances through creative ways using videos, PowerPoint presentations, posters, brochures, blogs and social media

- Textbook should contain activities which provide learners with links to econtent that they could use as a learning resource or as a model of a learning outcome

- Textbooks should provide activities present information, skills and qualities required for future jobs that are compatible with the $21^{\text {st }}$ century

- Textbook should present activities that focus on real world problems to encourage learners to conduct social experiments that will allow them to use and refine their social and communication skills in real-life situations

\section{REFERENCES:}

American Council on Teaching of Foreign Languages. (1995). Standards for foreign language learning preparing for the 21 st century. Alexandria: Author.

American Council on Teaching of Foreign Languages.(2011). $21^{\text {st }}$ Century Skills map. $\quad$ Retrieved from https://www.actfl.org/sites/default/files/pdfs/21stCenturySkillsMap/p21_world languagesmap.pdf. Accessed on 30 July 2016. 
Cohen, L., Manion, L. \& Morrison, K. (2007). Research methods in education. London: Routledge

Cunningsworth, A. (1995). Choosing your Coursebook. Oxford: Heinemann Garinger, D. (2002). Textbook selection for ESL classroom. Eric Digest, 2 (10)

Hammani, M., Ahssen, S. \& Tansaoui, L. (2007). Ticket 2 English students' book. Casablanca: D.I.O. El Hadita

Hassim, M., Blibil, M., \& Rasmy, A. (2007). Gateway to English 2. Rabat: Nadia Edition

Hutchinson, T., \& Torres, E. (1994). The Textbook as Agent of Change. ELT Journal, 48(4), 315-328

Iftanti, E. (2015). Investigating Inspiring English Lecturers in a Faith-Based Educational Institution: EFL Learners' Perception. Dinamika Ilmu, 15 (2), 2015.

Jibreel, I. (2015). Evaluating Blue Skies 6 with reference to Yemeni students. Arab World English Journal, 6(2): $372-384$

Krippendorff, K. (2013) Content analysis: An introduction to its methodology. CA: SAGE Publications, Inc.

Litz, D. (2005). Textbook Evaluation and EFL Management: A South Korean Case Study. Asian EFL Journal, 48:1-53.

McDonough, J., \& Shaw, C. (2003). Materials and Methods in ELT. Oxford: Blackwell.

Ministry of National Education. (2007). English Language Guidelines for Secondary Schools: Common Core, First Year, and Second Year Baccalaureate. Rabat: Author.

Najib, M., \& El Haddad, E. (2007). Insights into English 2. Rabat: Al Massar Edition

National Education Policy. (2012). Preparing 21st Century Students for a Global Society: An educator's guide to the 4Cs. Retrieved from http://www.nea.org/assets/docs/A-Guide-to-Four-Cs.pdf. Accessed on 30 July 2016.

Nurhayati, Dwi Astuti Wahyu. (2008a). Improving Students'English Vocabulary Mastery through Games (A Classroom Action Research in the Islam Kindergarten of Al-Irsyad Madiun in the Academic Year 2007/2008). Surakarta. Graduate School of Sebelas Maret University.

Pacific Policy Research Center. (2010). 21st Century Skills for Students and Teachers. Honolulu: Kamehameha Schools, Research \& Evaluation Division. Retrieved

from http://www.ksbe.edu/_assets/spi/pdfs/21_century_skills_full.pdf. Accessed on 30 July 2016.

Partnership for $21^{\text {st }}$ Century Skills. (2008). $21^{\text {st }}$ Century Skills, Education \& Competitiveness: A Resource and Policy Guide. Tucson, AZ: author. Retrieved

from http://www.p21.org/storage/documents/21st_century_skills_education_and_co mpetitiveness_guide.pdf. Accessed on 30 July 2016. 
Richards, J.C. (2001). Curriculum Development in Language Teaching. Cambridge: Cambridge University Press

Scott, C. L. (2015). The Futures of Learning 2: What Kind of Learning for the 21st Century? Education Research and Foresight Working Papers. Paris: UNESCO.

Sheldon, L. (1988). Evaluating ELT Textbooks and Materials. ELT Journal, 42(4), 237-246. 